\title{
Turning outsourcing inside-out? The case of the Mindfulness in Schools Project
}

\section{David Kirk}

\begin{abstract}
This paper provides an account of the use of programs in two schools developed by the Mindfulness in Schools Project (MiSP) as an example of the outsourcing of Health and Physical Education. The purpose of the paper is to show that outsourcing, in this particular case, is complex and does not match some of the expectations sometimes associated with this neoliberal practice in education. Responding to Penney and Mitchell's (2017) argument that outsourcing is a form of curriculum development from the 'outside-in', I suggest that the MiSP's work with schools is in contrast a form of 'turning outsourcing inside out'. I show that the success of the MiSP programs rested as much on teacher advocacy and commitment from inside schools as it did on the work of this external provider. I argue, moreover, that the practices of the MiSP placed limits on the extent to which it might generate revenue in order to protect the integrity of its approach. I conclude by considering whether these practices to safeguard integrity were justified, or whether they were another example of what Evans (2014) called 'intrusive pedagogies'. I also question the extent to which the strict terms and conditions the MiSP set for teachers' use of their programs is sustainable and feasible in the longer term.
\end{abstract}

\section{Keywords}

Mindfulness; outsourcing; health and physical education; commercialization; educational innovation

\section{Introduction}

Outsourcing has become a common and widespread practice in education systems of many post-industrial countries of the Global North, and increasingly so in the Health and Physical Education (HPE) curriculum area. Williams et al. (2011) and Williams and Macdonald's (2015) empirical work show the increasing prevalence and institutionalization of outsourcing in HPE in Australia, while Sperka and Enright's (2017) review suggests outsourcing is now a global phenomenon. Ball (2004) argued that outsourcing was a form of what he called 'exogenous privatisation' of education, involving private businesses external to the school delivering services formerly provided by schools or school districts themselves. Sometimes it is teaching or coaching personnel who are brought into schools because schools perceive themselves to lack this expertise (Griggs, 2010). Sometimes it is a curriculum resource or even a whole program that is incorporated into the school curriculum, as was the case for example of Daily Physical Education in Australia in the 1980s and 1990s (Tinning and Kirk, 1991). While outsourcing in these forms has been present in HPE since at least the 1980s, it was at this time a relatively rare occurrence. With the rise of neoliberal practices in education, however, outsourcing has become increasingly commonplace.

The commercialisation of the work of schools, as a practice associated with neoliberalism, has had a variety of consequences, according to HPE researchers. McCuaig et al. (2015) highlighted the rise of what they call the physical and health 'edu-business' and the consequent erosion of the school's social justice mission. Macdonald (2014) and Evans (2014) both argued that the pervasive influence of neoliberal practices in HPE prompts health and physical educators to think radically differently about their field. Echoing these sentiments, Penney and Mitchell (2017) proposed that all thinking about future possibilities for curriculum reform in HPE needs to take account of the growing legitimacy of outsourcing 
as a practice. Given its links to privatization and commercialization, outsourcing in HPE is also associated with profit making and taking. Gard and Pluim (2017) showed that this is clearly the case with Fitnessgram, a digitised physical fitness curriculum which was being used in an estimated 67,000 schools in the US.

While this literature acknowledges that outsourcing is a complex process, the connection with the commercialisation of state provided education, whether implicit or explicit in these analyses, is often portrayed in a negative light, as either undermining the educational mission of HPE or introducing or exacerbating inequality (Kirk, 2010). As both Penney and Mitchell (2017) and Gard and Pluim (2017) noted, an added concern is the influence of organisations external to schools over the curriculum and the learning experiences outsourced teaching and programs afford young people. At the same time, it is clear that the growing prevalence of outsourcing and its legitimisation in state education jurisdictions rests on widespread acceptance by schools and teachers. Any portrayal of outsourcing as, simply, a 'good' or a 'bad' thing is, then, unlikely to be accurate or helpful to health and physical educators interested in educational reform.

The purpose of this paper is to explore the complexity of outsourcing in HPE through the case of the Mindfulness in Schools Project (MiSP). Following Penney and Mitchell's (2017) account of 'reforming curricula from the outside-in', I will argue that the MiSP offers an example of turning outsourcing 'inside-out', where teachers on the inside, in the schools, were key protagonists for the use of MiSP programs. Indeed, as I will point out, the MiSP was at the time of the study not advertising its products, and in the case of both schools in this study the teachers learned about their programs by word of mouth, mostly from other teachers. Moreover, the teachers had to submit themselves to quite extensive training before they were allowed to purchase and access to the MiSP materials. These teachers were enthusiastic users and advocates of the MiSP programs, but they were at the same time sceptical about some of the 'strict terms and conditions' the MiSP applied. While these terms and conditions of use were viewed by the MiSP personnel as important for maintaining the integrity of their programs, they arguably placed limits on sales and thus on revenue generation. The picture of outsourcing that emerges is somewhat removed, I will argue, from the connotations of the notion of 'Education for Sale!' (Ball, 2004).

\section{The Mindfulness in Schools Project}

Richard Burnett, one of the co-founders of the MiSP, draws on Jon Kabat-Zinn to define mindfulness as "paying attention in a particular way: on purpose, in the present moment, and nonjudgmentally" (in Burnett, 2009, p.7). Kabat-Zinn's definition is also cited in a recent Campbell Systematic Review of Mindfulness Based Interventions (Maynard et al., 2017) of which MiSP is one of a dozen or more programs and is referred to consistently within this literature.

At the time of the study, MiSP offered two programs for pupils, one at primary school level and one at secondary school level. The primary school program was called 'Paws b', which stands for 'pause and breathe'. It was a six lesson program designed for children ages 7 to 11 , (https://mindfulnessinschools.org/what-is-b/paws-b-curriculum/). The '.b' program (stop and be) was a nine-lesson unit designed for 11-18 year olds (https://mindfulnessinschools.org/what-is-b/b-curriculum/). The MiSP offered, in addition, adult training programmes for teachers, school leaders and parents. Lesson packages with teacher notes and powerpoint slides for both the Paws $b$ and .b programs were available for purchase by teachers who had completed the required mindfulness training. In order to access the training program, teachers had to be able to show the MiSP that they had been practicing 
mindfulness themselves for a minimum of six months. Only teachers who completed the MiSP training could buy and use the materials for the Paws $b$ and .b programs.

\section{Research methods and design}

The research design followed the protocols developed for the larger study and are outlined in the first paper of this Special Issue. The MiSP was one of two external providers selected for study in the UK part of the project on the basis that their work was in the field of HPE, with a particular focus on mental health. The schools were selected from a pool provided by the MiSP personnel based on their accessibility and willingness to take part in the study.

Participants from the MiSP were 'Charlotte', the Operations Manager, 'Karen', the Research Manager, and 'Thomas', a Senior Trainer. Participants from Seymour College Junior School were 'Cathy', Depute Head Teacher, and 'Julia', Principal Teacher and lead teacher for the MiSP program. Participants from Flinders Primary School were 'Jennifer', Depute Head and lead teacher, and 'Elizabeth', the Head Teacher.

Both schools were located in the same city in Scotland. Seymour College was an independent, fee-paying school with Junior and Senior sections, located near the centre of the city. Its pupil population was drawn from across the city and its hinterland. Flinders Primary School was a state school again located near the city centre. Flinders' pupil population was drawn mostly from the local neighbourhood. In the case of both schools the majority of children lived in areas of low multiple deprivation (as measured by the Scottish Index of Multiple Deprivation, http://www.gov.scot/Topics/Statistics/SIMD).

Data for the study was produced from interviews with the individuals named above, and observations of two lessons each of Paws $b$ and .b. The main method used for data generation was semi-structured interviews using a list of topics developed by the larger project and tailored to suit the specific situations of the interviewees. The interviews with the MiSP staff were carried out on Skype and voice recorded for later transcription. The interviews with teachers and senior managers in the two study schools were carried out on-site and similarly voice recorded for later transcription. Lessons were observed in situ and detailed field notes made. Research and advocacy literature and a range of other support materials for MiSP programmes were also analysed, though these data are not reported here.

Interviews were transcribed and returned to the participants to check for accuracy. Only minor changes were made. The transcripts were analysed to identify themes and subthemes using axial coding consistent with a grounded theory approach (Charmaz, 2006). Themes emerged through an iterative process of organising data according to interview topics and new emerging categories. During the analysis process, the main themes were 'saturated' with data from the interviews, and triangulated with the observational and documentary data. Four main themes illustrating the process of turning outsourcing inside-out are outlined in the next section.

\section{The Mindfulness in Schools Project: Turning outsourcing inside-out?}

In order to explore the nature of the phenomenon of inside-out outsourcing, I consider first the nature of mindfulness as it was set out in the research and other support literature, as the participants in this study understood it, and why they thought it was needed in schools. Next,

\footnotetext{
${ }^{1}$ These names of individuals and schools are pseudonyms
} 
I examine the ways in which the MiSP message was marketed, which was a key aspect of the outsourcing process. Third, I investigate the features of fidelity and control (McCuaig and Hay, 2014) that sat at the centre of the schools working with the MiSP. Finally, I discuss the extent to which this approach might be sustainable considering the inevitable need for teachers to customise aspects of the mindfulness materials and due to the programs' location within broader curricular configurations in each of the two study schools.

What is mindfulness and why in schools? : 'the fundamental aim is to do with just training attention so that you can focus on present moment awareness'. (Charlotte, Operations Manager MiS)

Participants in the study were cautious about overclaiming for the benefits of mindfulness, but they nevertheless spoke with knowledge and enthusiasm about its potential. Charlotte, the MiSP Operations Manager, said:

It's not surprising that mindfulness has been seen very much as something that's used as a form of treatment or intervention because that's where its origins were when it was first brought to the west, you know, a secular context. So it's not surprising but it's much more than that. It's also about flourishing. (Charlotte, Operations Manager MiSP)

Cathy, Depute Head of Junior School at Seymour College, located this positive aspect of mindfulness training as helping children at all stages of the school deal with emotions and frustrations, while providing them with a vocabulary to express themselves:

I think it's being in the present and understanding yourself, understanding how you're feeling. And you do that with the early years children, you know, you teach them to begin with a lot of their frustrations are that they don't have the vocabulary to articulate how they're feeling. So you help them with the vocabulary and help them discuss their feelings. (Cathy, Seymour College Junior School)

Charlotte suggested that this development of a shared language to discuss their feelings and emotions was a life skill. Julia, Principal Teacher heading up the 'Resilience Program' at Seymour College Junior School, concurred that mindfulness provided a skill for life:

What's important is that we're giving our kids tools. We give them the tools for life and if we start in junior school and build on it right the way through the school then hopefully we're sending them out into the world not just with an education but with a good sense of how to care for their own wellbeing as well. (Julia, Seymour)

Jennifer, Depute Head and lead teacher of the Paws b programme at Flinders Primary School, talked about the kind of situation she typically experienced in her work that led her to pursue mindfulness training for herself:

Sometimes when you need to be with somebody, you actually have to be with them. I have to be listening. I can remember before I did it (practising mindfulness), trying to finish an email and a member of staff would come in and that was my moment to have my lunch, because I was on playground duty. I was eating a sandwich. I was writing an email. She was trying to tell me something. Actually, I didn't do any of those things well. I can't remember eating the sandwich. I actually sent an email with ' $J$ ' and a kiss 
on the end of it! I thought, it's not a way to live actually. It's not a way to be, that we just have this hamster on a wheel. (Jennifer, Flinders Primary School)

The 'hamster on a wheel' expression was used by other participants in the study and suggests that while flourishing and developing life skills are important benefits to young people, the management of stress is nevertheless another serious motivation for engaging in mindfulness as a practice, particularly as a way of coping with the ultra-busyness of the school environment. Jennifer provided another anecdote of one of her younger pupils also using what he had learned from his Paws b lessons to manage a stressful experience:

Anecdotally I hear lots from the teachers about the impact of the course and the children that come to me. One of my little boys in P2, he went to the dentist. His mum was chatting to me and he said, 'do you know what Mum? I just need you not to speak to me just now, because I need to do my mindful breathing before I go in there'. (Jennifer, Flinders Primary School)

There seemed then to be a consensus on the nature of mindfulness among the participants in this study, as a means of training the attention to focus on being in the present. The participants enthusiastically endorsed the potential of the programme, but they were aware too that benefits were not uniform, the same for all children, nor were they immediately evident. Thomas, one of the Senior Trainers on the MiSP team, captured well this caution in this comment about adults who come to mindfulness training expecting instant results.

Mindfulness is not a quick fix. For a lot of people in this world, they want a quick fix. They want a mindfulness tablet, and even the courses I teach for the adults, they're wanting to know why it hasn't worked after a week or two, and there's that expectation that things are going to change very quickly. You have to say part of this is patience and perseverance and accepting that things probably get a little bit tricky before they get easier. (Thomas, Senior Trainer MiSP)

Marketing the MiSP message: "The evidence is always the essential key to our message" (Karen, Research Manager MiSP)

Outsourcing rests on an assumption that a market exists for services and expertise in education, which in turn rests on a financial transaction between schools and external providers and which may supply an opportunity for profit-making and taking for the provider. According to the MiSP webpage (https://mindfulnessinschools.org/) at the time of the study, for a teacher to undertake the training and gain access to materials for the Paws b programme, the cost was $£ 465$ plus VAT, for .b $£ 625$ plus VAT, and for the School Mindfulness Leader programme, the cost was $£ 1050$ plus VAT. A one-day Seminar for School Leaders was provided at the cost of $£ 225$ plus VAT. On top of this was the cost of undertaking an adult mindfulness training course before teachers could access the MiSP programs. Given that any teacher who completed the training was not permitted to share her resources with other teachers in a school, these costs for a school were not inconsiderable, and could be very challenging if a teacher was to pay for herself. So the MiSP fits at least one assumption underpinning outsourcing, that is involves a financial transaction for services and materials.

As far as profit-making and taking is concerned, at this early stage in the evolution of the MiSP any profit made was reinvested as the organisation was seeking charitable status, which it achieved subsequent to the fieldwork being completed. 
At the moment we're mainly reinvesting in infrastructure. It's only recently that we got a proper database of client information and staff, you know, people to run projects. That's where our main outgoings are at the moment. We're always developing and continuing to develop the curricula. You know .b is now on phase 10 and paws $b$ is still being developed and the .b Foundations course is still being developed and then there's all these other new things that we're going to be rolling out next year. I think that's really where most of our money goes. (Charlotte, Operations Manager MiSP)

While there existed a range of providers of mindfulness and related forms of mental health programs, and thus there was a market for schools to make selections from, at the time of the fieldworkthe MiSP had done no direct marketing, as this brief snippet of conversation reveals:

Charlotte: We've got where we are through no real direct marketing at all.

Facilitator: So it's word of mouth?

Charlotte: It's nearly all word of mouth and it's quite striking because we were looking the other day. I think the first teacher training course happened in 2009. There were two that year I think. This year we've got 36 courses running so it has expanded very rapidly. (Charlotte, Operations Manager MiSP)

This situation was set to change, as the comments from Karen, Research Manager at the MiSP revealed, as the Paws $b$ and .b Foundations programmes were reaching the end of their development phase or just implemented. Given the caution surrounding overclaiming for the benefits of mindfulness training for young people, Karen made it clear that the message contained in any direct marketing would be based on the best available research evidence:

We have summaries of the evidence on our website, the evidence of the children and the evidence of the teachers. My understanding from meeting with the team on Tuesday was that the marketing will be around the.$b$ foundations course which is the course for teachers and start to, so that we can start to potentially create a cohort of teachers who are then potentially able to train (other teachers) to teach courses to children in their schools. That will be about making direct approaches to schools to say have you thought about this. But the blurb would be evidence based. (Karen, Research Manager MiSP)

Since the MiSP was proceeding for the most part on a word of mouth basis, Thomas described two possible ways in which this process tended to work:

There's the more formal approach where they (schools) would contact us and want us to go in to present to colleagues, and we have a presentation that we do to give them the background to everything. Then there's another approach where somebody within the school has already trained up and they invite colleagues in to watch them. (Thomas, Senior Trainer MiSP)

Neither of these approaches used cold-calling. The first relied on word of mouth and the second on an advocate on the inside of the school, preferably someone who was already a trained mindfulness practitioner. The latter was the case in both schools in this study. At Seymour College, according to Julia, she and several of her colleagues had shopped around before settling on Paws b: 
We went to some very interesting twilights as a department and tried all these different providers that are out there and we came out of some of them going there's absolutely no way we're going to listen to that person for eight weeks. We really trialled it ourselves as adults first. Then three or four of us went on a great course and thought okay, let's see what we can do. So we started doing that. Then I heard about Paws b and the trainer that we'd gone with as adults for the eight-week course (Breathworks) she'd gone to do some training with them (MiSP). I value her opinion and she said you know what, actually this is by teachers for teachers, you should look into it. (Julia, Seymour)

Advocates on the inside were key to the adoption of Paws b at Seymour College, as they were at Flinders also. Thomas also mentioned the importance of support from a senior member of staff in the school, which in the case of both schools in the study was crucial. At Seymour College, Depute Head Cathy said:

I did the eight-week training myself. Yes, I've taken part. I did volunteer. Well, my rule, I'm in charge of the curriculum all the way through. So when there's something like this and they're saying, we brought in philosophy, it's like I need to know about this. If we're going to invest in this and this is something that every child's going to have, then I need to make sure I'm happy with it and it's something that I believe will benefit all the children. (Cathy, Seymour)

Fidelity and control: 'you can't expect kids to buy in to mindfulness as a practice or even an exercise unless the person or the people around them who are teaching them are clearly walking the talk'. (Charlotte, Operations Manager MiSP)

One of the participants (Julia) was told that Paws b had been created by teachers for teachers. All of the core MiSP team were or had been teachers. All were also practitioners of mindfulness themselves. As Charlotte and Karen put it, they could all 'walk the talk':

Nearly everybody on the team, certainly in the core team, has got a longstanding mindfulness practice. Most of us have trained to teach adult mindfulness and have studied mindfulness in lots of different capacities. So we hope that we walk the talk with whatever it is that we do. (Karen, Research Manager MiSP)

This was essential not just for the core MiSP providers but for all teachers of mindfulness to children. According to Thomas:

The children know when they're being taught by somebody who does mindfulness and when they're just being taught by somebody who's trying to give them information. And even though that information will still help them, it won't help them, I believe, as much as somebody who is quite wise around what they're saying and quite measured in what they're saying, who is grounded within their own practice. (Thomas, Senior Trainer MiSP)

Being 'grounded in one's own practice' was, indeed, a strict requirement for access to the MiSP training and materials:

Absolutely at the heart of what we do is the fact that anybody who trains to teach our curricula has a practice of their own and it's an established practice. Because what underlies all of our materials is a fundamental understanding of the theory and practice involved in mindfulness and specifically mindfulness-based cognitive therapy and mindfulness-based stress reduction. On a practical level, the teachers need to know that 
stuff before they even begin to come and train with us. But very importantly, for their own wellbeing and in order to model what it is that they're teaching the kids, they need to have their own practice. We've got very strict prerequisites for our teacher training courses. (Charlotte, Operations Manager MiSP)

Julia at Seymour College recounted her experience of completing the application to do Paws b training:

You have to have done six months of personal practice, then you fill in an application form to get on the Paws b course. So they seem to be quite rigorous in who they're accepting on to their training which is in a way a very good thing. (Julia, Seymour)

Jennifer at Flinders Primary School pointed out these requirements for access to the courses were not conducive to the rapid spread of mindfulness in schools:

There is a bit of a bottleneck. There's a bottleneck in that you have to have a six months' practice of your own. Then getting onto the course and having the money to do that and then you can only really do that to your own class, with your own class, although the materials are very, very clear. They basically give you a script, but it's the practice in between and it's the whole understanding of what it means at its very roots. That's the important thing. They want to ring-fence the integrity of their product. (Jennifer, Flinders Primary School)

As Jennifer reported, once she had completed the training, only she was allowed to use the materials with her own class, and that she had to follow the 'script' provided for lessons. Julia confirmed this feature of the MiSP materials, noting "They're very much, 'you can't change the resources' and everything is locked down" (Julia, Seymour). Thomas explained that while the programs were scripted, these notes should ideally become a vehicle for the teacher's own practice:

Anybody can do an eight week course, take six months and then attend our curriculum training. It doesn't necessarily mean that they've embedded the practices. So those people who are coming to us with all that enthusiasm and inspiration, it's wonderful, but again, it's about grounding them, bringing them back to their own practice. I think the key thing is that okay, we've got 10 lessons. There's a script that goes with it to give people a sense of confidence in how it's told, but really, it's just a vehicle for our own practice. So I know that when I teach, I'm using the slides to kind of give them a focus and to guide me through what comes up and out. Parts of the script comes up and out through me, but what's really coming up through me is my own experience of mindfulness. That's what's doing the teaching, I feel, and that seems to have been increasingly so over the years. When I started I felt like I was delivering a curriculum. Now I feel like I'm living that curriculum, if that makes sense? (Thomas, Senior Trainer MiSP)

Thomas emphasised again the MiSP's point of conviction that teachers of mindfulness must also be practitioners of mindfulness. Nevertheless, he also made clear that the issue was also about fidelity and control, to prevent multiple versions of the MiSP programs being implemented:

We have very strict terms and conditions that tell people if they're going to use our .b curriculum and Paws b curriculum they can't change them. The language may be different, but the slides that they use are all sealed and they have to teach as-is with 
their own, as I said before, with their own practice coming up and through. If we're all teaching, as I say, 1400 people had open PowerPoints, there'd be 1400 different versions of .b, so what would .b be? (Thomas, Senior Trainer MiSP)

The teachers were, for the most part, supportive of these strict terms and conditions, the requirement for a personal mindfulness practice and the locking down of the materials. Cathy commented:

That's what we liked about Paws b. It's created by teachers for teachers and they're very careful about who they release it to. You have to have been through all your training. Just as here, you know, 'Julia' said, you're not going in and doing anything until you've taught it! (Cathy, Seymour)

Despite this appreciation of the MiSP's terms and conditions, and while working within these, the teachers themselves recognised that they had to customise any programme which originated from outside the school in order to meet their specific local needs. Cathy's colleague Julia talked about another teacher in the Seymour College Senior School who was using.$b$ in a specific way:

We've got a teacher in senior school she's done the.$b$ and we work very closely together her and I. She's head of S6. We were very much that it would be helpful to 'Seymourise' things as well. So she's taken it down a slightly different route and she's she's developed this love your mind and these mind apples that all the children get, a squeezy mind apple and they have to do the five things a day. So that's part of the mindfulness. We've taken that in to be part of our ethos. We're seeing it as a tool as opposed to rather than a blanket approach. (Julia, Seymour)

To 'Seymourise' was to customise, to recontextualise to a degree, the external resource. Julia had noted this need to 'Seymourise' in relation to the Paws b evaluation:

We have used the evaluations that come with the Paws b curriculum. We don't feel they particularly evaluate for us what we need to do. So actually we've just done our yearly evaluation as a department and that's what we've put down as one of our targets for next session. (Julia, Seymour)

As Julia explained, this was not so much a matter of taking anything out of the Paws b program, but instead adding to it:

We just feel that because we're doing it with P6 and P7, because we have quite an able cohort we're actually looking at adding to it as opposed to taking bits out. We're looking at actually trying to find a parent who is a neuroscientist or a brain surgeon and actually coming in and giving us CPD on the brain because the kids are asking us questions that perhaps we don't know the answers to. (Julia, Seymour)

Customisation and sustainability with a 'locked down' resource: "It's quite a difficult balancing act" (Julia, Seymour College)

At the same time, Julia reported that while the script was helpful to begin with, sheer repetition of the same lessons over and over required her to perform a 'balancing act':

I think for a class teacher the notes would be extremely helpful. I'm teaching this, I could be teaching this six times in a week. So by the end of your sixth time, you know. It's quite a difficult balancing act. I think having spoken to some of the teachers at 'Flinders', one of them was saying to me “"Julia' I don't speak like this!”. I was, like, I 
know. So it's trying to kind of match how you teach with what they've given you I think at times is a bit tricky. (Julia, Seymour)

We already noted Thomas's view that the programs became vehicles for the teacher's own personal practice of mindfulness. Nevertheless, Julia's comments raised a question about the sustainability of a program that might involve repeating the same lessons, word for word, up to six times per week. Added to this is the challenge mentioned by the Flinders teacher, of matching the script to personal teaching style.

The need to customise the MiSP programmes was also prompted by the context created by the wider curriculum of the schools. All schools in Scotland must work within the context of Curriculum for Excellence (CfE), which offers its own framework for teaching Health and Wellbeing and also concepts and resources. Within this broader governmental context for the curriculum, schools had their own specific priorities and initiatives. Jennifer noted for Flinders that "Our biggest focuses of the last year has been on emotional and mental health". She explained further:

We have a whole program of emotion talks, which is a really, really good program. It does dovetail with mindfulness. We're also very, very keen on the work of Carol Dweck and growth mindset, which also feeds into a lot of mindfulness. We feel that with the three things we've got going on that we actually are beginning to properly address the emotional and mental health of our pupils. (Jennifer, Flinders Primary School)

As Jennifer's comment revealed, the MiSP programs are not used in isolation. Similarly, at Seymour College, the school's specific priorities and preferences were in evidence:

We re-evaluated our whole resilience curriculum and we started with identifying our emotions in nursery and built it into what class teachers recognise as being difficult situations for children at different points in their school career and also feedback from parents. We picked the middle of the school and we went for the MindUP curriculum by Goldie Hawn. We started with that, just to kind of trial it and see if that was something, and we looked at optimism, and we looked at a very simple introduction to mindfulness. (Julia, Seymour)

For the teachers, 'tweaking' the program was in no way a matter of finding fault, but rather was a necessity in order to make it fit with their own priorities. As Julia commented:

When you look at Paws b it's very, very good. It's one of the best things I've ever been on in 20 years of teaching. It's one of the best resources I've come across. I think now that we've done it for a year like anything you need to make a couple of tweaks to make it suitable for our kids. Kids are fascinated by their own brain and fascinated by science and I think that Paws b's approach of looking at the brain and this is what's happening in your brain, it's those wonderful teacher moments where the lightbulbs go on above the head and you can see it happening. (Julia, Seymour)

This ringing and unsolicited endorsement of Paws $b$ supports the research studies to date that suggest the MiSP programs are well-liked by teachers and pupils, and that they work as part of the overall Health and Wellbeing curriculum. Notwithstanding this praise, it may not be credible that the MiSP programs will be able to be sustained over time as locked down resources, nor that teachers will always over time follow the script. 


\section{Conclusion}

My purpose in the paper has been to explore the notion of 'inside-out outsourcing' through the case of the MiSP, since it appears to offer a different model of relations between schools and an external organisation from the exogenous privatisation that might be associated with a notion such as 'Education for Sale!'. Certainly the data suggest that the MiSP, its programs and materials, were well regarded by the teachers in the two schools in this study. Moreover, the MiSP providers' insistence on maintaining the integrity of their programs with their 'strict terms and conditions', suggests a business model that is far from exploitative financially. This is because the requirement for personal mindfulness training and practice created a 'bottle neck' in the process of teacher professional development, thus limiting revenue generation. Word of mouth as the main means of advertising similarly was unlikely to fuel rapid growth.

The high level of fidelity and control MiSP insisted upon was also central to maintaining that integrity. At one level, this might be justified by the highly sensitive nature of the topic of mindfulness itself. Thomas at one point in his interview talked about the need to guard against children giving up too much personal information about themselves and their families, not exposing the 'soft underbelly of the children'. In lessons I observed, many children talked freely about personal matters such as things that worried them, though Jennifer (who was teaching one of the observed lessons) also showed awareness that responses from children had to be steered away from such matters. In this context, where children's health and happiness are the subject of the pedagogy, a high level of integrity and fidelity would appear to be appropriate.

On the other hand, there may be ways that the MiSP operates that are consistent with other outsourced services in HPE. I agree with Evans (2014) that surveillance and regulation of the most personal and intimate aspects of people's lives has been a real consequence of neoliberal practices in education and the kinds of markets they have created, intended or not. Furthermore, the self-surveillance he proposed comes with practices, such as mindfulness, may be a form of what he called 'intrusive pedagogy'. Evans asked whether school is a sphere of life where this king of pedagogy belongs? At the same time, one of the teachers in the study argued pragmatically that until other ways of relieving stress inducing pressures on young people could be found, mindfulness teaching in schools was essential. Both of the schools in this study located the MiSP programs within a constellation of other curriculum initiatives that sought to support young people's health and wellbeing. In this respect, the MiSP work was relevant to this other health and wellbeing work.

The locked down nature of the curriculum materials that make up .b and Paws $b$ may be justified given the sensitivity of the subject itself and the protection of the integrity of the project, but at the same time raise questions about the sustainability and indeed feasibility of this approach. In terms of curriculum renewal and development, it is not possible to take teachers out of the process, and the local context of implementation will exert forces for adaptation that external agencies ultimately cannot control (Kirk and Macdonald, 2001). The MiSP were clear in their commitment to using research, including feedback from teachers, to help develop their programs. But this is not the same thing as giving teachers 'spaces for manoeuvre' (Priestley et al., 2012) that would appear to be necessary for the creation of robust and educationally valuable programs. The teachers in this study were looking for those 
spaces while adhering as best they could to MiSP's terms and conditions. By all accounts, the schools in this study valued the expertise provided by MiSP, expertise that they themselves do not have. To turn the outsourcing process inside-out, however, it may be that external providers will need a more nuanced approach to fidelity and control than appears evident in this case if their programs are to have a sustained influence over time. 


\section{References}

Ball, S.J. (2004, June). Education for Sale! The Commodification of Everything? Presented at King's Annual Education Lecture, University of London. Retrieved from http://nepc.colorado.edu/files/CERU-0410-253-OWI.pdf\#

Burnett, R. (2009) Mindfulness in Schools: Learning lessons from the adults - secular and Buddhist. Self published.

Charmaz, K. (2006). Constructing grounded theory: A practical guide through qualitative analysis. London: Sage.

Evans, J. (2014) Neoliberalism and the future for a socio-educative physical education, Physical Education and Sport Pedagogy, 19(5), 545-558.

Griggs, G. (2010) For sale - primary physical education. $£ 20$ per hour or nearest offer, Education 3-13, 38(1), 39-46

Kirk, D. (2010) Physical Education Futures London: Routledge.

Kirk, D. and Macdonald, D. (2001) Teacher voice and ownership of curriculum change. Journal of Curriculum Studies 33(5), 551-567.

Macdonald, D. (2014). Is global neo-liberalism shaping the future of physical education? Physical Education and Sport Pedagogy, 19, 494-499.

Maynard, B.R., Solis, M.R., Miller,V.L. and Brendel, K.E. (2017) Mindfulness-based interventions for improving cognition, academic achievement, behavior, and socioemotional functioning of primary and secondary school students. Campbell Systematic Reviews 2017:5 DOI: $10.4073 / \mathrm{csr} 2017.5$.

McCuaig, L., Enright, E., Rossi, A., Macdonald, D. and Hansen, S. (2016) An eroding social justice agenda: The case of physical education and health Edu-business in schools. Research Quarterly for Exercise and Sport, 87(2), 151-164.

McCuaig, L. and Hay, P.J. (2014) Towards an understanding of fidelity within the context of school-based health education, Critical Public Health, 24 (2), 143-158,

Penney, D. and Mitchell, S. (2017) Reforming curricula from the outside-in, pp. 157-172 in C. Ennis (ed) Routledge Handbook of Physical Education Pedagogies, London: Routledge.

Priestley, M., Edwards, R., Miller, K., and Priestley, A. (2012) Teacher agency in curriculum-making: Agents of change and spaces for manoeuvre, Curriculum Inquiry, 42(2), 191-214.

Sperka, L. and Enright, E. (2017) The outsourcing of health and physical education: A scoping review. European Physical Education Review, 1-24, OnlineFirst.

Tinning, R. and Kirk, D. (1991) Daily Physical Education: Collected Papers on Health Based Physical Education in Australia. Geelong: Deakin University Press. 
Williams, B. J., Hay, P. J., and Macdonald, D. (2011) The outsourcing of health, sport and physical educational work: A state of play. Physical Education and Sport Pedagogy, 16(4), 399-415.

Williams, B. J., and Macdonald, D. (2015) Explaining outsourcing in health, sport and physical education. Sport, Education and Society, 20(1), 57-72. 